\title{
ANALISIS PENGARUH VARIASI KAMPUH PENGELASAN SMAW DC TERHADAP TEGANGAN TARIK, KEKERASAN, STRUKTUR MIKRO PADA BAJA KARBON RENDAH
}

\author{
Mochamat Sobirin*, Helmy Purwanto dan Imam Syafa'at \\ Jurusan Teknik Mesin, Fakultas Teknik, Universitas Wahid Hasyim \\ Jl. Menoreh Tengah X/22, Sampangan, Semarang 50236. \\ *Email : birintri@yahoo.co.id
}

\begin{abstract}
Abstrak
Penggunaan jenis kampuh yang berbeda sangat berpengaruh terhadap sifat fisik dan mekanik hasil pengelasan baja karbon rendah. Penelitian ini bertujuan mengetahui pengaruh hasil struktur mikro, pengujian tarik dan juga distribusi kekerasan. Penelitian ini menggunakan bahan pelat Baja karbon rendah dengan ketebalan $6 \mathrm{~mm}$. Selanjutnya spesimen dilakukan pengelasan dengan variasi jenis kampuh yang berbeda yaitu kampuh $V$, kampuh double V, kampuh $U$. Hasil struktur mikro pada daerah las pada kampuh $V$ adalah ferit widmanstatten dan ferit batas butir serta juga martensit. Pada kampuh Double V menghasilkan ferit batas butir yang berbentuk lembut. Pada pengelasan jenis kampuh $U$ menghasilkan ferit batas butir, Ferit widmanstatten dan martensit bilah. Hasil tegangan tarik yang paling tinggi 408.44 MPa terletak pada kampuh double V, sedangkan tegangan tarik dengan nilai rendah 391.45 MPa terletak pada kampuh $V$. Tegangan tarik maksimal nilai tertinggi 539.85 MPa juga terletak pada kampuh double V, sedangkan tegangan tarik maksimal dengan nilai rendah 486.88 MPa terletak pada kampuh V. Nilai kekerasan pada daerah las tertinggi adalah 83.33 HRB terjadi pada pengelasan dengan jenis kampuh double $V$, disebabkan hasil struktur mikro martensit bilah lebih banyak, dimana sifat martensit bilah itu keras. Nilai terendah adalah 78 HRB terjadi pada pengelasan dengan menggunakan jenis kampuh $V$.
\end{abstract}

Kata Kunci : SMAW, Struktur Mikro, kekerasan, Tegangan Tarik

\section{PENDAHULUAN}

Kemajuan teknologi dalam pembuatan konstruksi dengan bahan logam hampir pengerjaannya tidak dapat dipisahkan dari pengelasan, hal itu dikarenakan penyambungan dengan las mempunyai peranan penting dalam rekayasa dan reparasi logam. Pengerjaan konstruksi dengan bahan logam di saat ini banyak melibatkan unsur pengelasan khususnya bidang rancang bangun karena sambungan las merupakan salah satu pembuatan sambungan yang paling banyak digunakan dan secara teknis memerlukan peralatan, metode, proses dan ketrampilan yang baik bagi untuk mendapatkan sambungan dengan hasil yang baik. Penggunaan teknik pengelasan dalam konstruksi sangat luas yaitu antara lain: perkapalan, jembatan, rangka baja, bejana tekan, sarana transportasi, rel, pipa saluran dan lain sebagainya. Pembuatan konstruksi las yang sesuai rencana dan spesifikasi dengan menentukan semua hal yang diperlukan dalam pelaksanaan dipengaruhi beberapa faktor produksi. Faktor produksi pengelasan adalah jadwal pembuatan, proses pembuatan, alat dan bahan yang diperlukan, urutan pelaksanaan, persiapan pengelasan (meliputi: pemilihan mesin las, penunjukan juru las, pemilihan elektroda, penggunaan jenis kampuh (Wiryosumarto, 2000). Pengelasan berdasarkan klasifikasi cara kerjanya dapat dibagi dalam tiga kelompok yaitu pengelasan cair, pengelasan tekan dan pematrian. Pengelasan cair adalah suatu cara pengelasan dimana benda yang akan disambung dipanaskan sampai mencair dengan sumber energi panas. Cara pengelasan yang paling banyak digunakan adalah pengelasan cair dengan busur (las busur listrik) dan gas. Jenis dari las busur listrik ada 4 yaitu las busur dengan elektroda terbungkus, las busur gas TIG (Tungsten Inert Gas), MIG (Metal Inert Gas), las busur $\mathrm{CO}_{2}$, las busur tanpa gas dan las busur rendam. Jenis dari las busur elektroda terbungkus salah satunya adalah las SMAW (Shielding Metal Arc Welding).

Elektroda las dalam pengelasan SMAW dapat berpengaruh terhadap hasil pengelasan, salah satu Elektroda yang dapat atau sering di gunakan adalah E7016. Elektroda lain dapat menggunakan arus DC- dan DC+. Penggunaan arus berkisar antara 115-165 A, dengan interval arus tersebut, pengelasan yang dihasilkan akan berbeda-beda (Soetardjo, 1997). 
Tidak semua logam memiliki sifat mampu las yang baik. Bahan yang mempunyai sifat mampu las yang baik diantaranya adalah baja karbon rendah. Baja ini dapat dilas dengan las busur elektroda terbungkus, las busur rendam dan las MIG (las logam gas mulia). Baja karbon rendah biasa digunakan untuk pelat-pelat tipis dan konstruksi umum (Wiryosumarto,2000).

Salah satu penyebab terjadinya kerusakan atau patah pada pengelasan adalah penggunaan jenis kampuh las yang tidak sesuai dengan pembebanannya ketika proses pengelasan, hal ini disebabkan oleh tegangan sisa akibat masukan panas pada proses pengelasan selain itu penggunaan jenis kampuh las yang tidak tepat juga menyebabkan kegagalan dari sambungan las (Arham, 2016). Tujuan dari penelitian ini adalah mengetahui dan menganalisis tegangan tarik, distribusi kekerasan dan struktur mikro hasil pengelasan SMAW DC dengan variasi kampuh V, double $\mathrm{V}$ dan $\mathrm{U}$.

\section{METODOLOGI}

Bahan yang digunakan dalam penelitian ini adalah pelat Baja karbon rendah dengan komposisi kimia C 0.0911, Fe 99.38, Mn 0.3130, Si $0.0205, \mathrm{P} 0.0002$, Ni 0.0154, Al 0.0621, Cu 0.0640, Ca 0.0012. Persiapan Bahan Penelitian antara lain adalah Mempersiapkan bahan yaitu pelat Baja Karbon Rendah dengan ketebalan 6 $\mathrm{mm}$ lebar $100 \mathrm{~mm}$ dan panjang $200 \mathrm{~mm}$, dengan kampuh $\mathrm{V}$, double $\mathrm{V}, \mathrm{U}$.
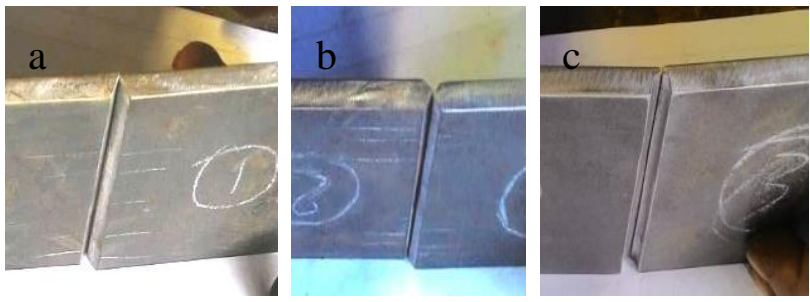

\section{Gambar 1. Bahan setelah dikampuh}

Mempersiapkan mesin las dan peralatan las berupa las listrik, pemegang elektroda serta jenis LB 52 U AWS (A 5.1. E7016), kabel las, topeng las, sikat baja, palu terak, tang las dan yang lainnya. Kemudian las kedua ujung benda kerja dengan hati-hati agar tidak terjadi perubahan bentuk dan defleksi dalam pengelasan benda kerja. Pengelasan dilakukan dalam ruangan. Bahan Seperti yang terlihat pada Gambar 1. Pemotongan dan pembuatan kampuh dengan menggunakan mesin $\mathrm{CNC}$, pelat di las dengan menggunakan mesin las SMAW DC arus $85 \mathrm{~A}$, dengan menggunakan elektroda E7016.

Hasil las di buat spesimen uji tarik sesuai dengan ASTM E 8M-sub size 9, uji kekerasan dan uji struktur mikro. Pembuatan spesimen uji tarik seperti terlihat pada Gambar 2.

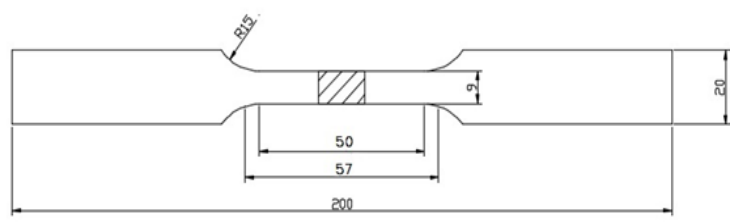

Gambar 2. ASTM E 8M-sub size 9

\section{HASIL DAN PEMBAHASAN}

Bahan yang digunakan dalam penelitian ini adalah pelat Baja karbon rendah dengan komposisi kimia C 0.0911, Fe 99.38, Mn 0.3130, Si 0.0205 , P 0.0002, Ni 0.0154, Al 0.0621, Cu 0.0640 , Ca 0.0012. Menurut Wiryosumarto (2000) baja karbon rendah adalah suatu baja paduan yang memiliki kandungan karbon sama dengan baja lunak, tetapi ada beberapa tambahan unsur paduan. Dari hasil pengujian komposisi kimia menunjukkan kandungan karbonnya adalah 0,0911\%. Menurut Amanto (2003) baja karbon dapat diklasifikasikan berdasarkan jumlah kandungan karbonnya, yaitu baja karbon rendah kandungan karbonnya rendah kurang dari $0,3 \%$, baja karbon sedang kandungan karbonnya 0,3$0,6 \%$, baja karbon tinggi kandungan karbonnya 0,6-1,5\%, jadi bahan yang digunakan dalam penelitian ini adalah termasuk baja karbon rendah.

\section{Hasil Foto Mikro}

Pengamatan posisi daerah hasil mikronya antara lain daerah raw material, HAZ, las. Seperti terlihat pada Gambar.3. Berdasarkan gambar tersebut terlihat dimana secara makro atau juga bisa disebut secara visual bahan pelat Baja Karbon Rendah yang telah dilas, kemudian juga dipotong serta dihaluskan.
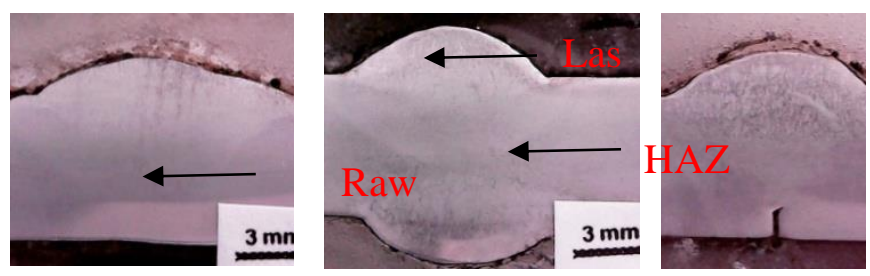

Gambar 3. Hasil pengelasan setelah dietsa 
Bahan yang dihaluskan sebelumnya kemudian dietsa, maka terlihatlah perbedaan antara pengelasan dengan Variabel jenis kampuh $\mathrm{V}$, jenis kampuh double $\mathrm{V}$ dan jenis kampuh $\mathrm{U}$.

\section{a. Struktur mikro Raw Material}
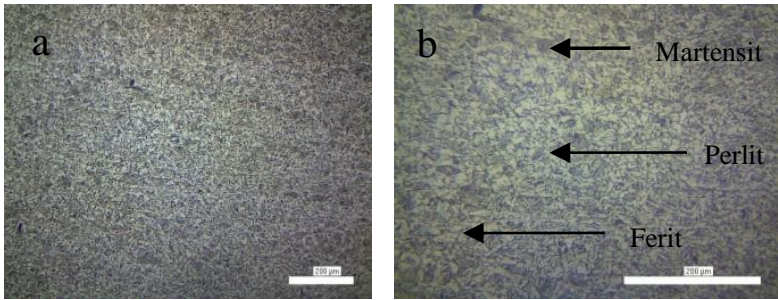

Gambar 4. Hasil struktur Mikro raw Material

Pada Gambar 4 terlihat sangat jelas bahwa hasil pengujian pada struktur mikro pada hasil uji metalografi raw material menunjukkan ada tiga fase yang terlihat yaitu: Fasa Ferit (kelihatan warna terang), Fasa Perlit (terlihat warna abuabu), dimana fase austenite di sini lebih mendominasi dan Fasa martensit (terlihat warna titik hitam kecil).

\section{b. Struktur Mikro Daerah Las}

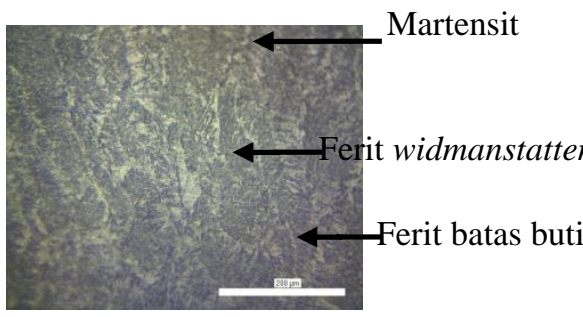

\section{Gambar 5. Struktur mikro Kampuh V}

Gambar 5 menunjukkan struktur mikro yang terbentuk adalah ferit widmanstatten, struktur mikro ini terbentuk pada suhu 750-6500 ${ }^{\circ} \mathrm{C}$ di sepanjang batas butir Austenite, ukuran yang besar dan pertumbuhan cepat sehingga memenuhi permukaan butirnya dan ferit batas butir serta juga martensit, struktur ini mempunyai sifat sangat keras dan getas sehingga ketangguhannya rendah (Sonawan, 2004).

Struktur mikro daerah las pengelasan Variabel jenis kampuh double $\mathrm{V}$ yaitu ferit batas butir yang berbentuk lembut, Ferit widmanstatten dan martensit bilah.

Ferit widmanstatten, struktur mikro ini terbentuk pada suhu $750-6500{ }^{\circ} \mathrm{C}$ di sepanjang batas butir austenit, ukuran yang besar dan pertumbuhan cepat sehingga memenuhi permukaan butirnya dan martensit pada gambar ini cukup banyak dan terdapat pada garis struktur kolumnar.

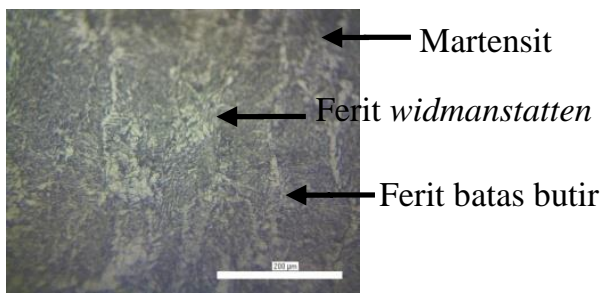

Gambar 6. Struktur mikro Kampuh Double V

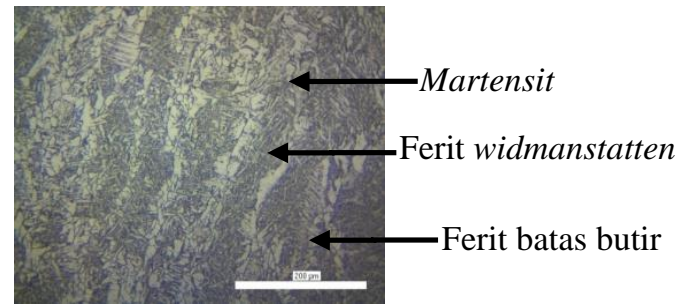

\section{Gambar 7. Struktur Mikro Kampuh U}

Gambar 7 Struktur mikro daerah las pengelasan Variabel jenis kampuh U yaitu ferit batas butir yang berbentuk lembut, Ferit widmanstatten dan martensit bilah, struktur ini mempunyai sifat sangat keras dan getas sehingga ketangguhannya rendah (Sonawan, 2004). Ferit widmanstatten dan ferit batas butir lebih mendominasi dan cukup banyak dan terdapat pada garis struktur kolumnar.

Tabel 1. Menunjukkan perbedaan hasil struktur mikro daerah las dan HAZ pada variable jenis kampuh yaitu kampuh $\mathrm{V}$, kampuh double $\mathrm{V}$ dan kampuh $\mathrm{U}$ dengan menggunakan pengelasan SMAW DC.

Pada Tabel 2. menunjukkan perbedaan hasil struktur mikro pada daerah HAZ dan daerah las. Perbedaan struktur mikro pada daerah HAZ menunjukkan bahwa pada jenis kampuh $\mathrm{V}$ menunjukkan struktur yang terbentuk adalah ferit halus, perlit kasar dan martensit. Struktur mikro lebih didominasi oleh perlit kasar yang terbentuk oval dan martensit sangat sedikit sekali. Pada jenis kampuh double $\mathrm{V}$ menghasilkan struktur yang terbentuk adalah ferit, perlit kasar dan martensit. Struktur mikro lebih didominasi oleh perlit kasar yang terbentuk oval dan martensit sangat sedikit.

Pada jenis kampuh $U$ menghasilkan struktur yang terbentuk adalah ferit, ferit batas butir dan perlit halus. Struktur mikro lebih 
didominasi oleh Ferit dan ferit batas butir yang terbentuk oval dan panjang, kalau dibandingkan dengan bentuk struktur pada logam induk sangat berbeda sekali karena struktur ini lebih rapat.

Tabel 1. hasil struktur mikro pada daerah HAZ dan daerah las

\begin{tabular}{|c|c|c|}
\hline $\begin{array}{c}\text { Jenis } \\
\text { Kampuh }\end{array}$ & HAZ & LAS \\
\hline V & & \\
\hline Double V & & \\
\hline $\mathrm{U}$ & & \\
\hline
\end{tabular}

Perbedaan struktur mikro pada daerah las menunjukkan bahwa pada pengelasan dengan jenis kampuh $\mathrm{V}$ menghasilkan struktur mikro yang terbentuk adalah ferit widmanstatten dan ferit batas butir serta juga martensit. Bentuk dari struktur mikro ini adalah bilah atau panjang. Pada pengelasan dengan jenis kampuh double $\mathrm{V}$ menghasilkan ferit batas butir yang berbentuk lembut, Ferit widmanstatten dan martensit bilah.

Ferit widmanstatten dan martensit pada gambar ini cukup banyak dan terdapat pada garis struktur kolumnar. Pada pengelasan dengan jenis kampuh $U$ menghasilkan ferit batas butir yang berbentuk lembut, Ferit widmanstatten dan martensit bilah. Ferit widmanstatten dan ferit batas butir lebih mendominasi dan cukup banyak dan terdapat pada garis struktur kolumnar.

Pada Gambar 8 menunjukkan bahwa hasil tegangan tarik yang paling tinggi $408.44 \mathrm{MPa}$ terletak pada pengelasan dengan menggunakan jenis kampuh double $\mathrm{V}$ karena struktur mikro martensit lebih banyak dibandingkan jenis kampuh yang lain. sedangkan tegangan tarik dengan nilai rendah $391.45 \mathrm{MPa}$ terletak pada pengelasan dengan jenis kampuh $\mathrm{V}$. Tegangan tarik maksimal nilai tertinggi 539.85 MPa juga terletak pada pengelasan dengan jenis kampuh double $\mathrm{V}$, sedangkan tegangan tarik maksimal dengan nilai rendah $486.88 \mathrm{MPa}$ terletak pada pengelasan dengan jenis kampuh $\mathrm{V}$.

\section{Tabel 2. Hasil Pengujian Tarik}

\begin{tabular}{|c|c|c|c|c|c|c|}
\hline $\begin{array}{l}\mathbf{N} \\
\mathbf{0}\end{array}$ & $\begin{array}{c}\text { Jenis } \\
\text { Kamp } \\
\text { uh }\end{array}$ & $\begin{array}{c}\text { Area } \\
(\mathbf{m m} \\
2)\end{array}$ & $\begin{array}{c}\text { Yield } \\
\text { Stress } \\
\text { (MPa } \\
\text { ) }\end{array}$ & $\begin{array}{c}\text { Max } \\
\text { load } \\
(\mathbf{N})\end{array}$ & $\begin{array}{l}\text { Max } \\
\text { stress } \\
\text { (MP } \\
\text { a) }\end{array}$ & $\begin{array}{c}\text { Elongati } \\
\text { on }(\%)\end{array}$ \\
\hline \multirow{3}{*}{1} & Logam & & 391.5 & 27824 & 515.2 & \\
\hline & induk & 54 & 11 & .9 & 7 & 27.54 \\
\hline & & & 391.4 & 26291 & 486.8 & \\
\hline \multirow[t]{2}{*}{2} & V & 54 & 53 & .6 & 8 & 22.13 \\
\hline & Double & & 408.4 & 29152 & 539.8 & \\
\hline \multirow[t]{2}{*}{3} & V & 54 & 4 & .2 & 5 & 26.13 \\
\hline & & & 403.0 & & 534.7 & \\
\hline 4 & $\mathrm{U}$ & 54 & 63 & 29568 & 4 & 22.66 \\
\hline
\end{tabular}

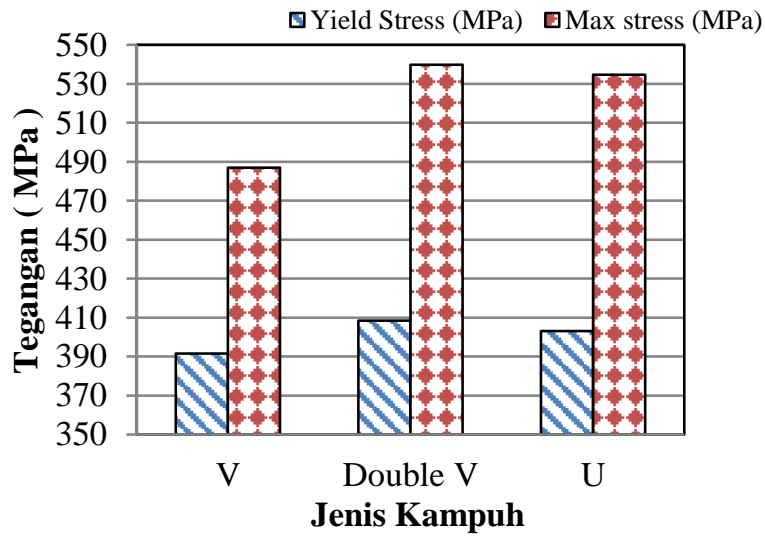

Gambar 8. Grafik Hasil Uji Tarik

\section{Hasil Pengujian Kekerasan}

Pada Gambar 9 Grafik kekerasan Rockwell menunjukkan bahwa kekerasan pada daerah HAZ yang paling tinggi adalah 78.66 HRB terjadi pada pengelasan dengan menggunakan jenis kampuh double $\mathrm{V}$, dan nilai kekerasan yang paling rendah adalah 75.33 HRB yang terjadi pada pengelasan dengan menggunakan jenis kampuh V.

Nilai kekerasan pada daerah las tertinggi adalah 83.33 HRB terjadi pada pengelasan dengan jenis kampuh double $\mathrm{V}$, disebabkan hasil struktur mikro martensit bilah lebih banyak, dimana sifat martensit bilah itu keras. Nilai terendah adalah 78 
HRB terjadi pada pengelasan dengan menggunakan jenis kampuh $\mathrm{V}$.

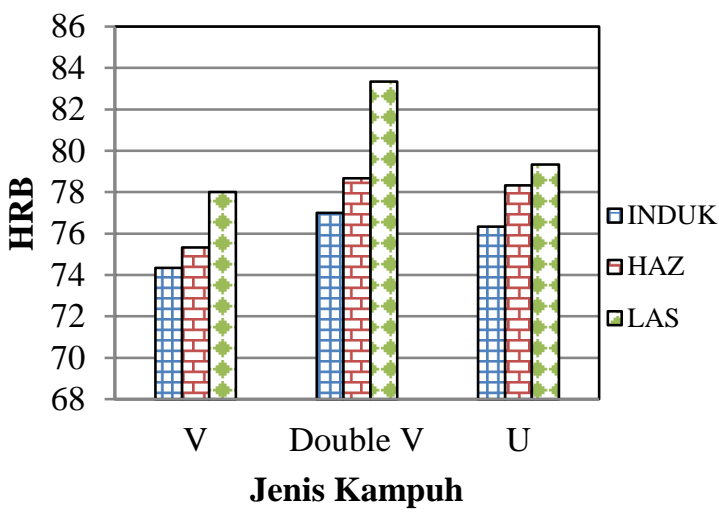

\section{Gambar 9. Hasil Kekerasan Rockwell}

Adapun hal-hal yang mempengaruhi hasil pengujian kekerasan bahwa secara umum untuk daerah las lebih keras dibandingkan daerah HAZ maupun logam induk, Karena suplai panas yang paling tinggi maka butir-butir logam akan rapat membentuk martensit bilah yang sifatnya keras.

\section{KESIMPULAN}

1. Struktur mikro pada daerah HAZ menunjukkan bahwa pada jenis kampuh $\mathrm{V}$ adalah ferit halus, perlit kasar dan martensit. Pada jenis kampuh double $\mathrm{V}$ menghasilkan struktur yang terbentuk adalah ferit, perlit kasar dan martensit. Pada jenis kampuh $U$ menghasilkan struktur yang terbentuk adalah ferit, ferit batas butir dan perlit halus. Perbedaan struktur mikro pada daerah las menunjukkan bahwa pada pengelasan dengan jenis kampuh $\mathrm{V}$ menghasilkan struktur mikro yang terbentuk adalah ferit widmanstatten dan ferit batas butir serta juga martensit. Pada pengelasan dengan jenis kampuh double $\mathrm{V}$ menghasilkan ferit batas butir yang berbentuk lembut, Ferit widmanstatten dan martensit bilah. Pada pengelasan dengan jenis kampuh $\mathrm{U}$ menghasilkan ferit batas butir yang berbentuk lembut, Ferit widmanstatten dan martensit bilah. Ferit widmanstatten dan ferit batas butir lebih mendominasi dan cukup banyak dan terdapat pada garis struktur columnar.

2. Hasil tegangan tarik yang paling tinggi 408.44 MPa terletak kampuh double V, sedangkan tegangan tarik nilai rendah $391.45 \mathrm{MPa}$ terletak pada kampuh $\mathrm{V}$.
Tegangan tarik maksimal nilai tertinggi 539.85 MPa terletak pada kampuh double $\mathrm{V}$, sedangkan tegangan tarik maksimal nilai terendah $486.88 \mathrm{MPa}$ terletak pada kampuh V.

3. Hasil nilai kekerasan Rockwell pada daerah HAZ yang paling tinggi adalah 78.66 HRB pada kampuh double $\mathrm{V}$, dan nilai kekerasan yang paling rendah adalah 75.33 HRB pada kampuh V. Nilai kekerasan pada daerah las tertinggi adalah 83.33 HRB pada kampuh double V. Nilai terendah adalah $78 \mathrm{HRB}$ terjadi pada pengelasan dengan menggunakan jenis kampuh V.

\section{DAFTAR PUSTAKA}

Arham, 2016, Pengaruh Jenis kampuh $V$ dan $X$ Terhadap Struktur Mikro dan Kekuatan Impak Pada Pengelasan Baja Karbon.

Amanto H., dan Daryanto, 1999 Ilmu bahan, cetakan pertama, Bumi aksara.

Wiryosumarto, H., 2000, Teknologi Pengelasan Logam, Erlangga, Jakarta.

Sonawan, H, 2003, Las Listrik SMAW dan Pemeriksaan Hasil Pengelasan.

Soetardjo, 1997. Petunjuk praktek las asitelin dan las listrik. 